\title{
PELATIHAN BAGI SISWA SMK SEBAGAI TEKNISI PEMBANGKIT LISTRIK TENAGA SURYA
}

\author{
Wahri Sunanda ${ }^{1}$, Rika Favoria Gusa ${ }^{1}$, Asmar $^{1}$, Muh. Jumnahdi ${ }^{1}$, Fardhan Arkan ${ }^{1}$, \\ Rudy Kurniawan ${ }^{1}$, Tri Hendrawan Budianto ${ }^{1}$, Nono Caryono ${ }^{2}$ \\ ${ }^{1}$ Jurusan Teknk Elektro Fakultas Teknik Universitas Bangka Belitung \\ ${ }^{1}$ SMKN 2 Pangkalpinang, Provinsi Kepulauan Bangka Belitung \\ E-mail: sunandawahri@gmail.com
}

\section{Article History: \\ Received :Juli 2021 \\ Review : Juli 2021 \\ Revised : Agustus 2021 \\ Accepted : Agustus 2021}

Keywords: Pelatihan, SMK, Pembangkit Listrik Tenaga Surya, Vokasi

\section{A. Pendahuluan}

Pembangkit listrik tenaga surya (PLTS) saat ini menjadi sumber energi alternatif yang masif digunakan di Indonesia, termasuk di Provinsi Kepulauan Bangka Belitung yang terdiri atas gugusan dua pulau dan banyak pulau kecil di sekelilingnya, diantaranya Nangka, Penyu, Burung, Lepar, Pongok, Gelasa, Panjang, Tujuh, Lima, Lengkuas, Selindung, Pelanduk, Seliu, Nadu, Mendanau, Batu Dinding, Sumedang dan pulau-pulau kecil lainnya (BPS Babel, 2019). Pertimbangan ini tentunya didasarkan atas nilai intensitas radiasi matahari $4,95 \mathrm{kWh} / \mathrm{m}^{2}$ hari (Yuant dkk, 2019) dan banyaknya pulau kecil yang dengan berbagai pertimbangan teknis, tidak cukup efektif dan efisien jika terhubung dengan kabel bawah laut.

Berdasarkan data PLN Unit Induk Wilayah Bangka Belitung (2021) bahwa penggunaan energi listrik yang bersumber dari energi surya sejumlah $80 \mathrm{~kW}$ dari total daya yang mampu dibangkitkan $282.609 \mathrm{~kW}$. Hal ini ini tentunya menjadikan pemicu untuk pemanfaatan energi surya di Bangka Belitung sebagai sumber energi listrik yang seiring dengan kebijakan yang tertuang dalam Rencana Umum Energi Daerah Provinsi Kepulauan Bangka Belitung Tahun 2019-2050 dalam upaya meningkatkan bauran energi baru terbarukan, diantaranya energi surya.

Dalam kaitan itu, perlu adanya upaya peningkatan kualitas sumber daya manusia yang akan menjadi motor dalam pemanfaatan dan perawatan pembangkit listrik tenaga surya, agar unjuk kerja pembangkit listrik tenaga surya agar unjuk kerja pembangkit listrik tenaga surya dapat selalu baik dalam rangka pemenuhan kebutuhan energi listrik. Salah satu sumber daya manusia yang ditargetkan dapat menjadi motor penggerak dalam perawatan pembangkit listrik tenaga 
surya adalah siswa-siswa Sekolah Menengah Kejuruan (SMK) yang memiliki pengetahuan dan kemampuan dasar tentang elektronika. Hal ini didasarkan dengan pertimbangan, bahwa siswa SMK memiliki kemampuan motorik yang sudah diajarkan dalam kegiatan praktikum-praktikum dengan jumlah lebih banyak dibandingkan teori, sehingga memungkinkan untuk ditingkatkan pemahamannya agar langsung dapat diterapkan di lapangan.

Beberapa penyuluhan dan pelatihan terkait pembangkit listrik tenaga surya juga telah dilakukan di beberapa institusi pendidikan menengah, diantaranya di SMP IT Almaka Jakarta (Christiono, 2019), SMA Negeri 6 Surakarta (Windarta, 2019), SMA Pancaran Berkat Jakarta Barat (Tambunan, 2020), SMK N 1 Cimahi (Santoso, 2020) dan di SMK MA'aruf NU Talang Kota Tegal (Syarifudin, 2020).

Sasaran akhir dari pelatihan ini adalah siswa-siswa SMK yang dilatih siap bekerja sebagai teknisi untuk mengobservasi, mengidentifikasi dan mencari solusi terhadap permasalahan teknik dari sistem pembangkit listrik tenaga surya baik di lokasi terpencil atau di pulau-pulau kecil yang masyarakat lokal belum tentu memiliki pengetahuan yang baik tentang sistem dan peralatan pembangkit listrik tenaga surya .

\section{B. Metode}

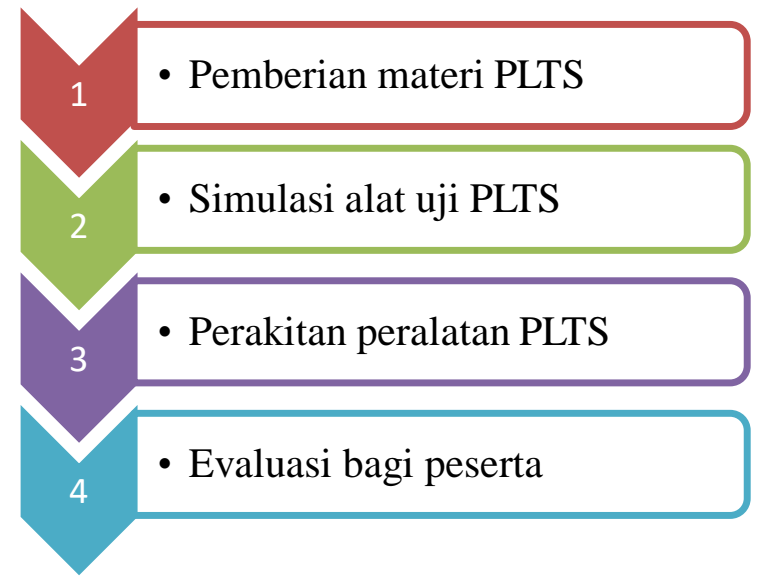

Kegiatan ini dilakukan melalui tahapan berikut:

\section{Pemberian materi tentang PLTS}

Materi diberikan oleh Dosen Jurusan Teknik Elektro Universitas Bangka Belitung terkait pengenalan, teori dasar dan implementasi PLTS kepada para siswa SMKN 2 Pangkalpinang

\section{Simulasi alat uji PLTS}

Simulasi dilakukan dengan simulator PLTS di Laboratorium Teknik Elektro Universitas Bangka Belitung yang terdiri atas sistem PLTS dengan cahaya buatan berasal lampu pijar.

3. Perakitan peralatan PLTS

Perakitan yang dilakukan oleh siswasiswa SMKN 2 Pangkalpinang menggunakan beberapa unit panel 50 $\mathrm{Wp}$, charge controller, inverter dan baterai/aki.

4. Evaluasi bagi peserta

Dilakukan sebagai evaluasi dari pemahaman siswa terhadap materi dan praktik PLTS di Laboratorium Teknik Elektro Universitas Bangka Belitung.

\section{Hasil dan Diskusi}

Kegiatan ini diikuti oleh 10 siswa SMKN 2 Pangkalpinang dalam periode waktu bulan Mei -Juni 2019. Pemilihan sekolah didasarkan atas kompetensi keilmuan sekolah yang salah satunya dalam bidang elektronika. Hal ini tentunya akan mempermudah dalam memberikan materi dan peningkatan kemampuan dasar siswa yang sudah dimiliki Materi awal yang diberikan terkait konsep dasar pembangkit listrik tenaga surya, agar siswa lebih memahami energi, usaha, daya, prinsip kerja pembangkit listrik tenaga surya, jenis pembangkit listrik tenaga surya yang terpasang stand alone dan yang terpasang on 
grid. Juga terkait komponen utama pembangkit listrik tenaga surya yakni ; solar panel, solar charge controller, baterai dan inverter.

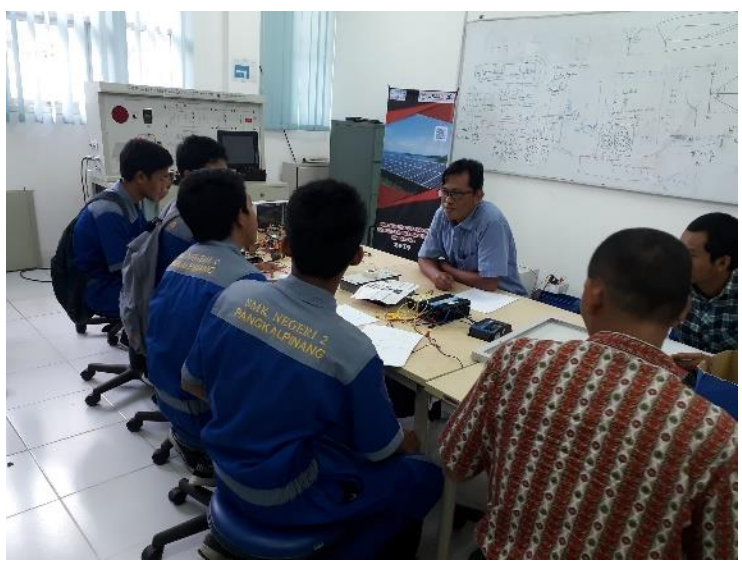

Gambar 2. Pemberian materi pengenalan pembangkit listrik tenaga surya

Selanjutnya siswa diberikan materi teknis terkait peralatan utama yang ada pada sistem pembangkit listrik tenaga surya, termasuk melakukan percobaan dan pengujian dengan panel surya yang tersedia beserta peralatan lainnya seperti; solar charge controller, baterai/aki, inverter, serta peralatan simulasi pembangkit listrik tenaga surya yang terdiri sel surya dengan sumber cahaya buatan dari lampu pijar serta tampilan pada monitor untuk melihat kinerja panel surya dengan beberapa simulasi yang dilakukan.

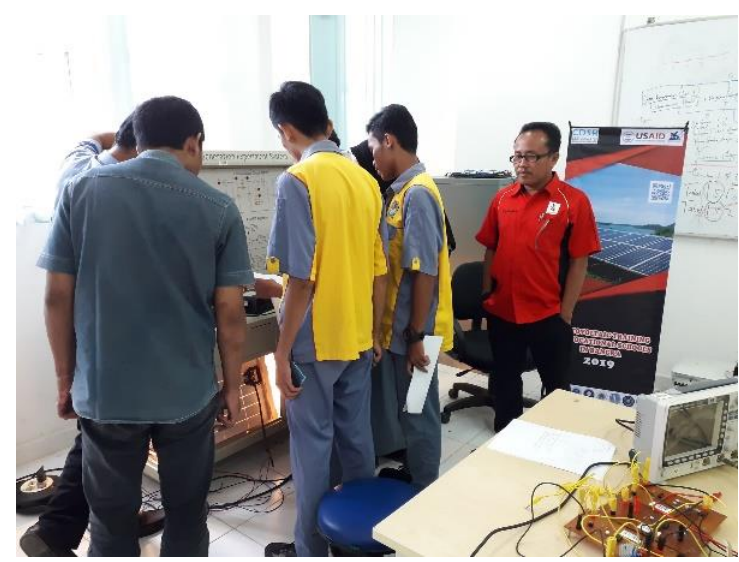

Gambar 3. Peralatan simulasi pembangkit listrik tenaga surya

Dalam pelatihan, para siswa juga langsung melakukan pengukuran dari panel surya, kemudian melakukan koneksi dengan charge controller, inverter dan baterai/aki, sehingga teori yang didapatkan langsung diimplementasikan. Beberapa parameter panel surya juga selalu disampaikan agar selalu menjadi perhatian, yakni ; irradiance (daya cahaya yang diterima panel surya dalam satuan $\mathrm{W} / \mathrm{m} 2), \quad \mathrm{V}_{\mathrm{oc}}$ (tegangan maksimum panel surya), $\mathrm{I}_{\mathrm{sc}}$ (arus hubung singkat/arus maksimum panel), MPP (maximum power plant, kondisi kerja pada daya maksimum), IMPP (arus pada daya maksimum), dan $\mathrm{V}_{\mathrm{MPP}}$ (tegangan pada daya maksimum).

Siswa juga diberikan pengetahuan tentang beberapa kurva/grafik sebagai indikator penting dari kinerja panel surya, yaitu; kurva hubungan tegangan-arus dengan beberapa kondisi intensitas penyinaran matahari, kurva hubungan tegangan-arus-daya serta pengaruh suhu terhadap tegangan dan arus.

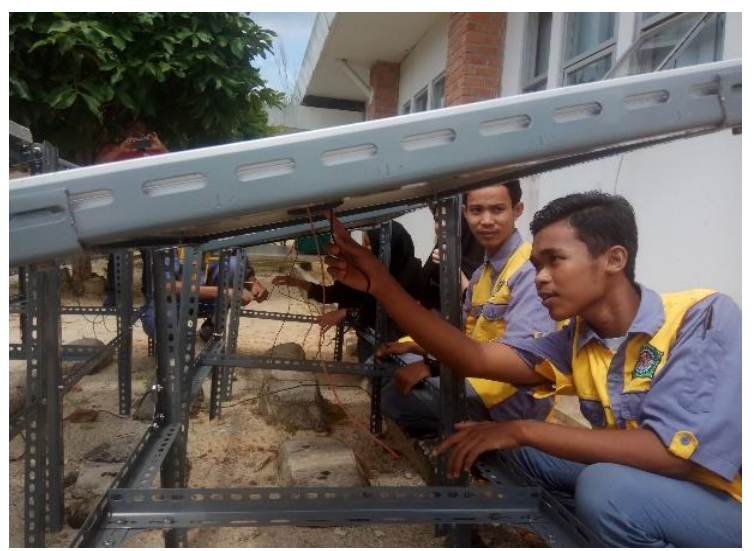

\section{Gambar 4. Pengukuran langsung oleh} siswa SMK

Sebagai evaluasi bagi siswa dilakukan uji kemampuan individu dengan tiap siswa melakukan perakitan panel surya dan peralatan lainnya dengan 3 skema, yakni ; skema pertama panel surya dikoneksikan 
dengan DC-DC converter, lalu DC-DC converter yang terhubung dengan baterai dan DC-DC converter yang terhubung dengan beban DC, skema kedua panel surya dikoneksikan dengan DC-DC converter, lalu DC-DC converter yang terhubung dengan baterai dan DC-DC converter yang terhubung dengan inverter lalu dengan beban/peralatan yang input tegangan berupa tegangan AC, skema ketiga panel surya terkoneksi dengan tie grid inverter dan berikutnya terhubungan dengan jaringan listrik PLN.

Dalam evaluasi, beberapa parameter yang harus dikalkulasi yakni; kondisi maximum power plant, tegangan dan arus panel surya, tegangan dan arus pengisian baterai, tegangan dan arus beban, efisiensi, waktu pengisian baterai, waktu pemakaian baterai, jumlah energi yang dihasilkan dan kesesuaian kapasitas peralatan yang digunakan.

Pelatihan ini tentunya akan diikuti pelatihan berikutnya dalam upaya menambahan jumlah sumber daya manusia yang siap menjadi teknisi pembangkit listrik tenaga surya minimal untuk memenuhi kebutuhan lokal di Provinsi Kepulauan Bangka Belitung serta juga untuk menyelaraskan dengan tujuan pendidikan vokasi yang sedang gencar diinisiasi oleh pemerintah dalam rangka pemenuhan kebutuhan sumber daya manusia terampil dan siap pakai.

\section{Kesimpulan}

Pelatihan ini menjadi bagian penting dalam rangka penyiapan sumber daya manusia siap pakai khusus di bidang pembangkit listrik tenaga surya. Kebutuhan sumber daya manusia bidang ini akan terus mengalami peningkatan seiring dengan kebijakan pemerintah untuk meningkatkan bauran energi yang bersumber dari energi terbarukan, diantaranya energi surya.

\section{Daftar Referensi}

Statistik, B. P. (2019). Babel dalam angka. Badan Statistik Propinsi Kepulauan Bangka Belitung.

Bangka Belitung, PLN UIW. (2021). Bauran Sistem Pembangkit Bangka dan Belitung. PLN Unit Induk Wilayah Bangka Belitung.

Bangka Belitung, Provinsi. (2019). Peraturan Daerah Nomor 13 Tahun 2019 tentang Rencana Umum Energi Daerah Tahun 2019-2050. Propinsi Kepulauan Bangka Belitung

Tiandho, Y., Dinata, I., Sunanda, W., Gusa, R. F., \& Novitasari, D. (2019, April). Solar energy potential in Bangka belitung islands, Indonesia. In IOP Conference Series: Earth and Environmental Science (Vol. 257, No. 1, p. 012022). IOP Publishing.

Tambunan, J. M., Pramono, T. J., Sitorus, M. B., Aziz, H., Yayi, S., \& Pawenary, I. P. M. (2020). Aplikasi Lampu Penerangan Rumah Tinggal Sederhana (Solar Home System) Berbasis Tenaga Surya Di SMA Pancaran Berkat Jakarta Barat. TERANG, 2(2), 117-125.

Windarta, J., Sinuraya, E. W., Abidin, A. Z., Setyawan, A. E., \& Kusuma, A. (2019). Penerapan Teknologi Pembangkit Listrik Tenaga Surya (PLTS) di SMA Negeri 6 Surakarta sebagai Sekolah Hemat Energi dan Ramah Lingkungan. Prosiding: Konferensi Nasional Matematika dan IPA Universitas PGRI Banyuwangi, 1(1), 215-227.

Syarifudin, S., \& Budi, S. S. (2020). UPAYA PENINGKATAN PENGETAHUAN ENERGI TERBARUKAN DI SMK MA'ARIF NU TALANG KOTA TEGAL. Jurnal Pengabdian Masyarakat Bumi Raflesia, 3(2).

Santoso, H. B., Saodah, S., \& Utami, S. (2020). SOSIALISASI DAN 


\section{IMPLEMENTASI RENEWABLE}

ENERGY DI SMKN 1

CIMAHI. Jurnal DIFUSI, 3(1), 4444.

Christiono, C., Samsurizal, S., Pratama, R., 15.
Ratnasari, T., \& Fikri, M. (2019).

Penyuluhan Pemanfaatan Energi Terbarukan (PLTS) di SMP IT Almaka Jakarta. TERANG, 2(1), 10- 